\title{
AS DIMENSÕES ESTÉTICA E POLÍTICA DA FORMAÇÃO DE PROFESSORES PARA A REDE PÚBLICA MUNICIPAL DE UBERABA - MG
}

\author{
AESTHETIC AND POLITICAL DIMENSIONS OF TEACHER \\ TRAINING FOR THE MUNICIPAL PUBLIC SCHOOLS OF \\ UBERABA - MINAS GERAIS STATE (BRAZIL)
}

\author{
Sueli Teresinha Abreu-Bernardes*
}

\begin{abstract}
Resumo
Este artigo apresenta algumas reflexões que embasaram as análises sobre a formação continuada de professores da rede municipal de ensino de Uberaba - MG. Para compreender o sentido de formação, são analisadas a dimensão estética, sobretudo na paidéia grega e em Gaston Bachelard, e a dimensão política, segundo o pensamento de Gramsci. A implantação do regime escolar de ciclos representou um avanço na Educação do município em questão. No entanto, os professores não foram suficientemente formados para essa proposta pedagógica e a reação a ela parece relacionar-se mais ao aspecto ideológico do que às possíveis limitações de uma metodologia de ensino coerente à inovação implantada.
\end{abstract}

Palavras-chave: Formação de professores. Dimensões estética e política. Rede municipal.

\begin{abstract}
The present article offers some reflections that have underpinned the analysis of the continuous training of teachers of the municipal schools of Uberaba - MG (Brazil). To understand the meaning of training, we have analyzed its aesthetic dimension, especially in the sense of the Greek paideia and in the interpretation of Gaston Bachelard, as well as its political dimension, according to Gramsci's thought. The implementation of the cycle-oriented school system represented a breakthrough in the Education in the studied municipality. However, teachers were not sufficiently trained for this pedagogical proposal, and the reaction to it seems to relate more to the ideological aspect of the proposal than to the possible limitations of a teaching methodology consonant with the implemented innovation.
\end{abstract}

Keywords: Teacher Training. Aesthetic and Political Dimensions. Municipal School System.

\section{A dimensão estética de formação}

Por onde começar a análise e a discussão sobre a formação do professor? Como apresentar diagnóstico e propostas de formação de educadores considerando a diversidade de sentidos que as atividades dessa natureza apresentam? De um lado, as políticas educacionais identificadas em legislações de uma Secretaria Municipal de Educação, com sua concepção dúbia entre capacitação e formação, e, do lado oposto, o departamento responsável pela execução dessa política, com registros, ações e referenciais próprios. Como enfrentar a situação desafiante de fazer a leitura solicitada e propor alternativas para as limitações encontradas, respeitando as tendências, as concepções e os gestos dos que fazem a história da Educação na rede municipal da cidade mineira de Uberaba, com um olhar crítico e a partir de pressupostos bem definidos?
Com todas essas indagações e mais algumas, aceitei o convite feito pela equipe de transição na área de Educação para participar do estudo sobre a formação inicial e continuada dos professores e demais profissionais da Educação dessa rede municipal. Ao se definir o corpo de análise, procurei, inicialmente, aprofundar o conhecimento sobre o sentido de formação e suas implicações em propostas formativas docentes. Além da preocupação teórica, busquei dados no Relatório Técnico da Equipe de Transição - área de Educação (2004) sobre o trabaIho realizado junto à equipe constituída pela Secretaria Municipal de Educação de Uberaba, MG.

O objetivo deste estudo é apresentar reflexões sobre o sentido de formação nas dimensões estética e política, pensamento construído no contexto de transição de um governo municipal. Para contextualizá-lo faço um recorte das atividades da área de Educação e escrevo, brevemente sobre o

\footnotetext{
*Professora do Programa Pós-Graduação em Educação - Mestrado da Universidade de Uberaba - UNIUBE. E-mail: gui2009@terra.com.br
} 
regime de Ensino Fundamental e as propostas formativas.

Este texto é, por conseguinte, construído, sobretudo, a partir de uma investigação teórica sobre concepções alternativas às propostas predominantes de formação continuada de professores, e tenho como referencial a fenomenologia de Gaston Bachelard e concepções de Gramsci. Recorro, ainda, à análise documental do relatório das atividades de coleta e análise de dados da realidade escolar municipal do final de 2003.

Para alcançar a compreensão do conceito de formação, parti do entendimento de que a ação formadora considera a pessoa como um ser humano integral, com múltiplas dimensões. Essa formação será continuada se alcançar níveis mais elevados na educação formal ou se aprofundar conhecimentos já existentes. Tal concepção expressa uma visão de homem e de mundo e uma concepção de Educação que se fundamenta em um profundo respeito e reconhecimento da condição e das potencialidades humanas.

Esse conceito distancia-se de capacitação que significa proporcionar uma capacidade a ser obtida pelos professores por meio de um curso. Essa concepção, de fundamento mecanicista, considera o docente incapacitado. Aparta-se, igualmente, do sentido de qualificação que busca desenvolver certas qualidades já existentes, ou de atualização, que tem por objetivo oferecer informações aos professores sobre fatos do momento.

A formação, no sentido em discussão, remete à paidéia na Grécia antiga e representa uma busca de pensar a dimensão estética desse agir educativo. Segundo Jaeger (1995, p.24), "educação e formação têm raízes diversas. A formação manifesta-se na forma integral do Homem, na sua conduta e comportamento exterior e na sua atitude interior". Ela supõe uma imagem de homem ideal e o que é nela fundamental é a beleza, no sentido de forma desejada.

É necessário salientar, ainda, segundo Jaeger (1995, p. 25), que "o tema essencial da formação grega é antes o conceito de areté, que remonta aos tempos mais antigos". Nossa língua materna não possui termo equivalente, porém, "a palavra 'virtude', na sua acepção não atenuada pelo uso puramente moral, e como expressão do mais alto ideal cavalheiresco unido a uma conduta cortês e distinta e ao heroísmo guerreiro, talvez pudesse exprimir o sentido da palavra grega" (JAEGER, 1995, p. 25). O conceito de areté define, pois, o ideal da formação helênica.

A formação integral e o conceito de areté são mais bem entendidos quando associados à ideia de harmonia do grego em sua cosmovisão antiga. Esse sentido de harmonia relaciona-se ao de música e aplica-se também à natureza, à Filosofia, à arte e à Educação. É ainda Jaeger (1995, p. 206) quem salienta a "íntima relação entre a matemática pitagórica e a música" e "a importância da música na primitiva formação dos gregos”.

Desde Homero, a música abarca além das funções recreativas, as ético-cognoscitivas, pois era indispensável no acompanhamento do canto ou da dança; era essencial na educação da classe aristocrática e um meio para colocar em evidência, suscitar sentimentos ou recordar situações peculiares. Na rapsódia VIII da Odisseia (2003, p. 157), Homero invoca "o divino aedo, Demódoco, a quem a divindade concedeu [...] o dom de deleitar com o seu canto, quando o coração o incita a cantar". E em várias outras passagens são descritas as indicações da lira sonora para ser tocada nas "danças acompanhadas de canto" bem como os cantos melodiosos dos amores de Ares e de Afrodite e os diversos cantos inspirados dos aedos.

Roque (s.d. apud TOMÁS, 2002, p. 47) afirma que "a educação grega era essencialmente musical, paidéia mousiké, e devia constituir um conjunto harmônico na formação do homem". Essa formação apresenta-se de tal forma que todos os domínios estabelecem relações de interdependência. A relação mútua entre música e harmonia, aliada a um caráter de fundo pedagógico, se irradia por todas as atividades educacionais, por apresentar-se como um poderoso instrumento de efetivação do ideal da paidéia grega.

Foi da conexão entre a música e a matemática pitagórica, lembra Jaeger (1995, p. 207) que "nasceram as ideias pedagógicas mais profundas e de maior influência entre os Gregos", pois o conhecimento da essência e do ritmo que emerge da estrutura da música apresenta uma quase ilimitada possibilidade de aplicação a todas as esferas da vida. Assim, a harmonia é entendida como o principio do cosmos e exprime a relação das partes com o todo. Essa ideia influencia todos os aspectos da vida grega, manifestando-se na arquitetura, na poesia, na retórica, na religião, na ética. A força normativa da descoberta da harmonia estende-se a todos os aspectos do pensamento helênico desde os clássicos, e se transpõe para o interior humano dando os pressupostos para sua formação.

Se na antiga Grécia busquei uma dimensão estética para pensar o sentido de formação, também na contemporaneidade essa linha de pensamento pode ser refletida. Para o filósofo Bachelard (1998, p. 18),

[...] a imaginação inventa mais que coisas e dramas; inventa vida nova, inventa mente nova; abre olhos que têm novos tipos de visão. [...] Terá visões se se educar com devaneios antes de educar-se com experiências, se as experiências vierem depois como prova de seus devaneios. 
As dimensões estética e política da formação de professores para a rede pública municipal... 207

O que nos torna humanos está, precisamente, nessas potencialidades criadoras, nesse poder de inventar o que não existe ainda, caracterizandonos como seres "artistas" em nossas possibilidades de instaurar outras realidades a partir do fazer ser o que não é. Nessa perspectiva, criar não é descobrir o oculto das coisas, mas fazer a materialidade ser o que não é na produção do conhecimento.

Essas reflexões expressam uma "antropologia escolar", segundo expressão de Fabre (1995, p. 2). Essa antropologia e a epistemologia da sala de aula lidas nos livros de Bachelard dirigem-se a um tema: a formação do sujeito.

Esse conceito é empregado pelo filósofo da imaginação, que o considera mais abrangente do que a noção de Educação. O educar ainda estaria muito relacionado à tradição que compreende o processo de conhecimento como o ato de repetir e de memorizar ideias. "Há uma preocupação fundamental em Bachelard que é mostrar em que consiste a formação do sujeito no seu esforço de produção de conceitos e no seu esforço de vivenciar imagens poéticas, ou seja, no seu esforço de razão e de imaginação". (BULCÃO, 2002, p. 284).

Em "O Ar e os Sonhos" leio: "um objeto poético deverá [...] absorver ao mesmo tempo todo o sujeito e todo o objeto." (BACHELARD, 1990a, p. 87). Essa subjetividade não exclui voltar-se para o objeto. As transformações do objeto são importantes para esse filósofo, pois as imagens materiais iniciam seus devaneios. O que constitui o centro dessa relação com o mundo é a maneira como a natureza aparece à consciência, sobretudo, por meio dos escritos dos poetas e prosadores sensíveis a ela. A imagem poética é uma forma de conhecimento, não é simplesmente um maravilhar-se. Não há, pois, uma única forma, que seria a da ciência, de estudar o real.

Pela imaginação abrimos para o futuro, para o devir. "Com a poesia a imaginação coloca-se na margem em que precisamente a função do irreal vem arrebatar ou inquietar - sempre despertar - o ser adormecido nos seus automatismos". O conhecimento do irreal e do real nos vem por meio do poeta que "é aquele que conhece, isto é, que transcende, e que dá nome ao que conhece". (BACHELARD, 1990a, p. 15-18).

O que o sonhador de palavras nos convida a estudar é o devaneio poético. Para ele toda a polifonia dos sentidos acorda e se harmoniza no devaneio poético que a escuta e a registra. "Se o mundo não fosse a princípio o meu devaneio, então o meu ser seria imediatamente encerrado em suas representações, sempre contemporâneo e escravo de suas sensações. Privado da vacância do sonho, ele não poderia tomar consciência de suas sensações". (BACHELARD, 1990a, p. 169). Assim, para conhecer o mundo, só por meio do devaneio poético que nos possibilita esse conhecimento que antecede a construção dos conceitos científicos. Criar saberes supõe uma evolução imaginativa que nos leva do devaneio fundamental a um conhecimento discursivo. Daí a importância do poeta. É ele que conduz o sujeito por esse caminho de devanear.

Como, então, entender um processo de formação humana que não considere o desenvolvimento da sensibilidade para reacender devaneios, reiniciar sonhos e recompor a vida imaginária? $\mathrm{O}$ resultado de uma formação sem essa abrangência não seria apenas o de uma pessoa que não sonha, mas seria o de alguém que não conhece o real a partir de um devaneio que se aprende a viver.

O filósofo sonhador transmite um sentido de formação do sujeito que necessariamente passa pela poesia, ou pela imagem poética, ou pelo devaneio poético. Existem afirmações no círculo bachelardiano sobre a existência de duas vertentes no pensamento do filósofo da imaginação criadora: uma, a científica, outra, a poética. Na verdade, é possível uma leitura diferente. Penso que a imaginação insere-se no pensamento bachelardiano em ambas, como um todo. (ABREU-BERNARDES, 2008, p. 78).

Ao pensar a ciência e o novo espírito científico, Gaston Bachelard expressa pelo menos dois sentidos do termo formação. No primeiro, a formação do espírito científico tem como predomínio a ruptura com o espírito pré-científico, em sua reconstrução histórica. O espírito científico contemporâneo é compreendido por ele como um processo de superação dos limites e obstáculos contidos na pré-ciência, vítima das metáforas. Penso agora em uma frase de Bachelard (1998, p. 4) em "A água e os sonhos": "ocorre sempre assim: na ordem da filosofia só se persuade sugerindo sonhos fundamentais, restituindo aos pensamentos suas avenidas de sonho". Publicado originalmente em 1941, três anos após "A formação do espírito científico", o autor faz, ele mesmo, um movimento de ruptura com os próprios conceitos. Não há aqui incoerência, mas a expressão de um movimento de retificação.

Fazendo eco a José Américo Motta Pessanha, "na verdade, o que Bachelard conquista a partir dessa época - para ele e para nós - são os fundamentos da legitimidade do devaneio, os motivos que tornam o sonho imprescindivel à arte e à vida". (PESSANHA, 1994, p. 21).

No segundo sentido, a formação adquire um sentido reformador e autorreflexivo em que o ensino de ciências está associado à produção científica. $O$ espírito científico nasce de uma forma livre, não escolarizada, transformando, reciprocamente, a ciência e o pensamento científico. 
Professores presos a uma visão reprodutivista do processo ensino aprendizagem substituem descobertas por aulas, por vivenciarem a verticalidade na relação professor-aluno. É um alto desprezo instaurar, sem recíproca, a inflexibilidade na relação escolar. "A nosso ver, o princípio pedagógico fundamental da atitude objetiva é: quem é ensinado deve ensinar. [...] Não basta ao homem ter razão, ele precisa ter razão contra alguém". (BACHELARD, 1999, p. 300).

Essa tensão necessária ao processo formador que nega o conhecimento que não se nega a si mesmo abrange, também, a incorporação do erro. Longe de ser evitada e dominada, a experiência pedagógica de errar é buscada como processo das invenções da pesquisa e do ensino, como essencial na formação do espírito científico. Esse processo é sempre renovado, sempre aberto ao diálogo, em constante provocação salutar em busca de garantias de cientificidade.

Utilizando outros percursos, mas sempre com uma visão orgânica que apreende o todo com uma profunda intuição, que considera as tensões que provocam a harmonia e que compreende o conhecimento intimamente ligado à arte e à poesia, Bachelard alcança, como na paidéia, um sentido de formação em que "o espírito humano abandona a ideia de um adestramento em função de fins exteriores e reflete na essência própria da educação". (JAEGER, 1995, p. 14).

\section{A dimensão política}

Se essas reflexões satisfaziam, inicialmente, um desejo de buscar pressupostos, desde os mais remotos, para expressar o sentido de formação do qual partira, outra dimensão também foi pensada. E foi em Gramsci e em autores brasileiros que se aproximam de seu pensamento que busquei esse conteúdo.

Uma primeira observação refere-se ao rompimento de paradigmas empreendido por Gramsci. A primeira ruptura diz respeito à afirmação de que a filosofia é algo muito difícil e que deve ser desenvolvida por cientistas especializados ou por filósofos profissionais. Se é possível elevar o nível da sociedade, é preciso quebrar mitos, como por exemplo, o da filosofia ser restrita a um grupo, pois todos os homens são capazes de ter uma atividade intelectual própria, crítica e autônoma.

Como demonstrar que todos os homens são filósofos? Gramsci afirma que todos são filósofos, pois "até mesmo na mais simples manifestação de uma atividade intelectual qualquer, na 'linguagem', está contida uma determinada concepção de mundo" O pensador italiano aponta para uma construção humana que possa criticar sua própria concepção de mundo a fim de participar de maneira crítica e consciente da construção histórica do mundo, sendo "guia de si mesmo", sem aceitar "passiva e servilmente" do exterior "a marca da própria personalidade". Quando isso não é feito, passamos a pertencer "simultaneamente a uma multiplicidade de homensmassa”. (GRAMSCI, 2004a, p. 93-94).

Nesse processo de desmistificação da filosofia, Gramsci diz que não há uma filosofia e sim diversas filosofias, ou seja, diversas concepções de mundo correspondentes à atividade real de cada um. Tanto a atividade intelectual como as ações dos homens simples expressam tais concepções. A organicidade do pensamento e a solidez cultural só ocorrerão se entre os homens existir a mesma unidade que deve acontecer entre a teoria e a prática, se os intelectuais forem organicamente os intelectuais [das] massas, ou seja, se tiverem elaborado e tornado coerentes os princípios e os problemas que [as] massas colocam em sua atividade prática, constituindo assim um bloco cultural e social. (GRAMSCI, 2004a, p. 100).

Essa atividade crítica possibilita a formação do homem socialista e os partidos políticos são importantes na "elaboração e difusão das concepções do mundo, na medida em que funcionam quase como 'experimentadores' históricos de tais concepções" (GRAMSCI, 2004a, p. 105). O papel do partido é relevante na formação humana. Cabe a ele selecionar individualmente a massa atuante nos campos teórico e prático. "Por isso, pode-se dizer que os partidos são os elaboradores das novas intelectualidades integrais e totalitárias, isso é, o crisol da unificação de teoria e prática entendida como processo histórico real". (GRAMSCI, 2004a, p. 105).

Gramsci também compreende que o processo educativo é decisivo na formação humana: "a escola é o instrumento para elaborar os intelectuais de diversos níveis [...] quanto mais extensa for a 'área' escolar e quanto mais numerosos forem os 'graus' 'verticais' da escola, tão mais complexo será o mundo cultural, a civilização de um determinado Estado." (GRAMSCI, 2004b, p. 9).

Segundo minha leitura do filósofo italiano, essa relevância do processo educativo assim se explica: todo o processo de formação da "nova cultura" cria relações pelas quais ele se dá e que são relações de hegemonia. Como toda relação de 'hegemonia' é necessariamente uma relação pedagógica, a Educação assume um papel preponderante na criação da nova cultura. Considerando que a relação educativa não se limita às relações especificamente da escola, mas existe em toda a sociedade em seu conjunto e em todas as relações dos indivíduos, os instrumentos dessa formação são os mais diversos. Tendo já destacado o papel "pedagógico" do partido político, importa ver a escola como uma das mais 
As dimensões estética e política da formação de professores para a rede pública municipal... 209

relevantes organizações culturais, tanto para a formação dos intelectuais quanto para a difusão crítica e a socialização das verdades já descobertas que possam tornar-se elementos de orientação junto ao maior número de homens. A condução do proletariado a uma concepção de vida superior e a sua instrumentação para se tornarem dirigentes, marca a função da escola na criação da nova cultura e a formação do novo Estado. A escola, que tem como um de seus objetivos a organização da cultura, deve manter suas ligações com o partido para que não se desvincule de seu significado político. O alcance de uma nova cultura só se realizará na hegemonia política e sua função é elaborar, difundir e realizar uma nova concepção de mundo e não apenas criar um novo Estado.

Nesse contexto, o principio educativo exige uma escola capaz de superar o elitismo. Gramsci escreve que o ensino profissional prevalece sobre a escola formativa. Mas "o aspecto mais paradoxal reside em que este novo tipo de escola aparece e é louvado como democrático, quando, na realidade, não só é destinado a perpetuar as diferenças sociais, como ainda a cristalizá-las". (GRAMSCl, 2004b, p. 49).

A formação das camadas populares supõe uma democracia política, ou seja, o respeito à cidadania. Isso significa não apenas qualificar o operário, mas possibilitar a cada cidadão

[...] tornar-se 'governante' e que a sociedade o ponha, ainda que abstratamente, nas condições gerais de poder fazê-lo: a democracia política tende a fazer coincidir governantes e governados [...] assegurando a cada governado o aprendizado gratuito das capacidades e da preparação técnica geral necessária a essa finalidade. (GRAMSCI, 2004b, p. 50).

Para atender a esse propósito, a escola idealizada por Gramsci deve ser uma escola inicial única de cultura geral, humanista, formativa, que oferecesse de modo equitativo o desenvolvimento das capacidades de trabalhar manualmente (tecnicamente, industrialmente) e de realizar um trabalho intelectual. Esse seria o único modo de não acolher apenas "uma pequena elite de senhores e mulheres que não devem pensar em preparar-se para um futuro profissional". (GRAMSCI, 2004b, p. 33).

Essa concepção de formação humana do autor dos "Cadernos do Cárcere" supõe que o homem deve educar-se científica e culturalmente até os níveis mais complexos mantendo, porém, uma intensa ligação com sua base popular e com o seu senso comum. A escola precisa desenvolver a capacidade de trabalhar a parte técnica e profissional, mas, ao mesmo tempo, precisa formar o intelectual orgânico que tenha condições de se tornar governante.

Dessas reflexões, inferem-se os elementos que constituem a natureza do trabalho do educador.
Intrinsecamente, existem as atividades de ordem intelectual: o educador "usa as ideias para atuar sobre as consciências que se transformam não só no nível da aquisição de conhecimentos (nível cognitivo), mas também no nível da orientação e produção de finalidades (nível teleológico)". (SILVA, 1992, p. 33).

Essas atividades intelectuais na escola são entendidas, geralmente, de modo injusto e equivocado: divide-se a Educação entre os que têm a função de criar e os que apenas reproduzem o que lhes é apresentado. Esse é o modelo que a tradição da sociedade capitalista traz para a escola. Observase, ainda, que essa dicotomia entre criadores e reprodutores da Educação vem sempre "respaldada" na exigência de um rigor científico. Na verdade, as razões são políticas, de desejo de controle. (BRANDÃO, 1982, p. 78).

É preciso considerar, também, que o professor de sala de aula não pode dispensar os outros níveis da função intelectual. Há um trabalho intelectual coletivo em relação à sociedade, à cultura e à escola em todas as dimensões. A tensão necessária não é entre os intelectuais, mas entre os intelectuais e os empeciIhos ao desenvolvimento da classe trabalhadora.

$\mathrm{O}$ educador escolar, além do conhecimento científico e da arte de "fazer vir ao mundo um saber que já estava lá e pedia para nascer" (CHAUÍ, 1982, p. 56), necessita de uma formação que recupere "a ligação da prática educativa com a educação política, em cujo âmbito se desenvolve a consciência de classe". (SILVA, 1992, p. 40). Esse vínculo não ocorre apenas na formação de uma consciência crítica e criativa, de caráter subjetivo, mas na ligação concreta com a classe trabalhadora em sua luta e desenvolvimento histórico, alcançando um reconhecimento mútuo de pertença.

É na compreensão de sua identidade como professor, trabalhador do ensino e sujeito político que a consciência profissional do educador se desenvolve.

\section{O distanciamento do processo formativo}

Selecionei para discussão apenas um aspecto identificado no trabalho realizado na passagem de governo e registrado no Relatório Técnico. (ABREUBERNARDES, 2004). Essa dimensão refere-se à realidade do Ensino Fundamental. Nele identifiquei que, na década de 1990, foi implantado o regime de ciclos nas escolas municipais uberabenses. Muitas críticas de educadores, políticos e integrantes da sociedade de um modo geral, foram ouvidas em relação aos ciclos. Penso poder afirmar que há mesmo uma tendência em associar ciclos à deterioração (que não posso afirmar que existe, pois a análise não contemplou esse aspecto) da qualidade do ensino. 
Segundo Freitas (2004, p. 10), o dilema entre série, progressão continuada ou ciclo "esconde, de fato, um dilema sobre que papel atribuir ao processo de avaliação escolar". A questão, de natureza ideológica, é entre conservadores, liberais e progressistas: os primeiros optam pela seriação formal e a avaliação reprovatória e excludente, apontando o professor e a escola como responsáveis pelo êxito ou fracasso do ensino. Os liberais inspiram a progressão continuada que,

[...] do ponto de vista curricular, apesar das junções de séries, continua tratando cada ano escolar de forma seriada e vê os conteúdos escolares como conjuntos de competências e habilidades a serem dominados pelos alunos.

A progressão continuada não se contrapõe à seriação [...]. Ela simplesmente limitou o poder de reprovar que a avaliação formal tinha ao final de cada série, introduziu recuperação paralela e tentou 'gerenciar' mais de perto o sistema educacional com avaliações de sistema e maior controle da escola. [...] A questão, portanto, não é optar entre progressão continuada ou séries, mas entre "avaliar com poder de reprovar ou não". (FREITAS, 2004, p. 10 , grifos do autor).

Os progressistas, comprometidos com as transformações sociais, pensam na reorganização e redefinição do tempo e dos espaços escolares, como os liberais têm feito, embora com outro sentido e finalidade. Nessa linha progressista é que discutimos os ciclos, como propostas de alteração dos tempos e dos espaços da escola de maneira global. Essa organização pedagógica pressupõe uma concepção de conhecimento como processo de construção e reconstrução, sendo revestido de sentido a partir das experiências socialmente significativas para as idades dos alunos. Os que propõem os ciclos consideram os fatores externos à escola: políticos, socioeconômicos e culturais, e valorizam esses saberes.

O espaço escolar é entendido como um local em interface com a realidade do entorno da instituição e é regido por princípios democráticos. Destacamse as vivências de reflexão crítica e uma avaliação emancipatória, o que supõe um tempo diferenciado de aprendizagem e recursos apropriados às dificuldades do aluno. [...] Tal enfoque avaliativo conduz à redução da reprovação, [...] além de permitir que o estudante se veja como sujeito de um processo que visa construir o seu conhecimento. (FREITAS, 2004, p. 14, grifo nosso).

Essa conceituação aproxima-se do sentido da "escola de Gramsci" em que a formação abrange o conhecimento universal, a formação política, o desenvolvimento da criticidade, o preparo, enfim, para uma nova cultura. E essas propostas são possíveis apenas em um desenho curricular mais integrado, flexível e contextualizado, em que os ciclos são uma opção.
A concepção de ciclos implantada na década de 1990 em Uberaba inseriu-se no Projeto de Escola Cidadã do Município de Uberaba, MG e teve como modelo os "fundamentos de uma escola públicapopular-autônoma nos parâmetros da concepção do Instituto Paulo Freire" (PRAIS; SILVA, 2000, p. 15) sob o ideário de Paulo Freire, José Eustáquio Romão e Moacir Gadotti. Essa escola foi proposta pelos seus idealizadores mineiros com o objetivo de "formar o cidadão para controlar o mercado e o Estado, sendo, ao mesmo tempo, pública quanto ao seu destino, isto é, para todos, estatal quanto ao financiamento e democrática e comunitária quanto à sua gestão". (GADOTTI, 2000, p. 1).

Após a definição das bases político-filosóficas da "Construção Amorosa da Cidadania" (denominação do projeto municipal de Educação à época), buscaram-se mudanças no sentido da organização do universo escolar (tempo e espaço), tendo como objetivo a ampliação da ação educativa. Documento da época, "Escola cidadã - Educação: construção amorosa da cidadania" expressa que "a instituição do regime de ciclos [...] organiza o seu trabalho em torno do princípio da justiça social". Nesse mesmo texto é escrito com ênfase que o "regime de ciclos não significa promoção automática, mas uma aprendizagem efetiva pelo respeito ao tempo de cada um". (PRAIS; SILVA, 2000, p. 25).

No entanto, os professores não foram suficientemente formados para essa proposta pedagógica, conforme depoimentos registrados no Relatório Técnico da Equipe de Transição - Área de Educação (2004). A reação negativa de muitos ao regime de ciclos parecia relacionar-se mais ao aspecto ideológico do que às possíveis limitações de uma metodologia de ensino coerente à inovação implantada. Essa ideologia se expressava em frases como: "o que é preciso, é ensinar o aluno a ler, a escrever e a contar", presente no discurso de professores da rede, de pais de alunos e mesmo de alguns políticos que se preparavam para assumir o poder, quando apontavam o que eles chamavam de má qualidade no ensino. (ABREU-BERNARDES, 2004, p. 7).

Mesmo existindo a oferta de múltiplos e variados minicursos no Centro de Formação Permanente de Professores da rede, o CEFOR, os quais eram muito solicitados pelos professores, não se observou nenhum espaço para discussão da dimensão política do trabalho dos profissionais da Educação, da profissionalização docente, sejam gestores, professores, especialistas ou técnicos administrativos.

No entanto, considero passível de crítica o fato de que as expectativas frustradas com as mudanças no regime de ensino não provocaram um questionamento das limitações relativas às condições pedagógicas dos educadores e das escolas; às exigências oriundas das políticas educacionais; às condições 
As dimensões estética e política da formação de professores para a rede pública municipal... 211

de trabalho e à organização do tempo e do espaço escolar. O movimento de reação conduziu a um fundamentalismo, juntando-se princípios, ideários e práticas pedagógicas de tendência tradicional, visíveis em declarações com enfoque nas habilidades básicas de letramento e cálculo. E, como consequência, a proposta emergente de formação dos professores enfatizava, sobretudo, a "capacitação" para ensinar essas habilidades. (ABREU-BERNARDES, 2004, p. 16).

Na perspectiva descrita nas linhas anteriores, essa proposta reducionista afasta-se do sentido de formação aqui refletido. Isso porque as diferentes dimensões humanas são negligenciadas na ação educativa, perde-se o sentido reformador e autorreflexivo do ensino e esquece-se que não só por meio da ciência é possível estudar o real. Além disso, a proposta de "formação" que emergia das discussões restringia-se ao preparo do professor para ensinar o ato mecânico de ler signos e relacionar números sem considerar tais habilidades como partes de um processo criativo.

Lembrando reflexões bachelardianas de Bulcão (2002, p. 295), a formação do ser humano está ligada não só à razão "que se retifica e se refaz inesgotavelmente", mas, do mesmo modo, "ao processo criativo próprio da imaginação que instaura ininterruptamente imagens sempre novas". A poesia, desde Homero e Hesíodo, e tão refletida em Bachelard, expressa esse outro modo de pensar a essência do ser, e é uma ação alternativa, mas também essencial, para a formação do sujeito. $O$ ensino instrumental, restrito ao cognitivo, aproxima-se de um adestramento em função de fins exteriores - como o de atender às exigências do mercado - e deixa de refletir na essência própria da Educação.

É, então, pensando em outro modo possível de se pensar a formação do sujeito que trago para a discussão um cientista social. Sobre a questão do "ler, escrever e contar", esse autor afirma:

Ao priorizar a educação básica escolar, restrita à aprendizagem das habilidades cognitivas básicas, as propostas do Banco Mundial indicam que o discurso da centralidade do conhecimento, a despeito do enunciado, configura-se como um artifício de retórica e de adesão às premissas do neoliberalismo, reduzindo o processo de formação a uma visão de racionalidade instrumental, tutelada, restrita e funcional ante o conhecimento universal historicamente produzido. (DOURADO, 2002, p. 241).

Uma reflexão política e poética de Brandão sobre essa mesma questão ilustra, também, como a discussão estética e política se interagem:

Quando a educação da sala de aula de meninos e meninas re-aprenderá que a mais importante função da "análise léxica" na escola não é apenas o ensinar a "falar e a escrever corretamente"? Mas é levarmos, por este caminho, a nos abrir desde a infância a totalidade de criação e de maravilha de nossa própria cultura, e a de outros povos, realizados como uma fala entre pessoas ou como escrita dirigida a pessoas [...] Que outro motivo para a gramática que eu aprendo, senão o habilitar-me a uma capacidade inesgotável de saber ler e viver a poesia de um Carlos Drumond de Andrade ou [a prosa poética] de um João Guimarães Rosa?[...] Por que não pensar que a razão de ser da matemática é ensinar pessoas a pensar com mais lucidez, com mais sabedoria e com mais criatividade? [...] Quando esquece seus disfarces, a educação utilitária pergunta: "o que é que precisa aprender uma aluna de quarta série para passar-de-ano e ser promovida (como no exército, como na fábrica, como no emprego) para a quinta série? Por que não dizer essa pergunta de outra maneira: "o que é que precisa aprender e saber uma menina de nove anos para viver da maneira mais completa e profunda possível a experiência única e irrepetível de ter nove anos?". (BRANDÃO, 2002, p. 91).

Essa lógica de "educação de resultados" e de "educação seriada da pressa do mercado" subordinam os processos de aprender aos resultados do aprendizado, em que pessoas são pensadas como "produtos da escola". No entanto, afirma Brandão (2002, p. 92), a Educação deve partir do reconhecimento de que "um direito-dever essencial em cada uma e em cada um de nós é o de viver sem limites utilitários a procura do saber e a experiência de aprender".

\section{Considerações finais}

No contexto do trabalho de uma equipe de educadores durante a mudança de um governo municipal, originou-se esta reflexão sobre concepções de formação. À discussão técnico-pedagógica, trago também ideias sobre outras dimensões: a artística e a política. Penso que não se trata de fragmentar, de ver o homem em aspectos distintos, e nem de menosprezar o imperativo da formação pedagógica. Ao contrário, significa retomar a pessoa em sua integridade, considerando toda a condição humana e, não apenas, algumas dimensões de sua existência. Discutir a formação do educador sem contemplar o desenvolvimento da sensibilidade, a vivência emocional, imaginativa, criadora e intuitiva; sem considerar a dimensão política do trabalho docente, significa tentar decompor o que existe como unidade. Esta ênfase na formação humana por meio da arte e da discussão política é a contribuição que reconheço neste artigo.

Ao observar discussões e propostas de formação de professores em torno da implantação de um regime de ciclos, vejo que, anterior às críticas de natureza pedagógica e debates ideológicos, deve predominar o refletir sobre concepções que embasem qualquer inovação no sistema de ensino e que 
abranjam os sentidos estético e político. Os projetos pedagógicos enraizados em tendências tradicional ou crítica de Educação precisam estender o olhar para aspectos que permanecem na penumbra quando se debate ou se propõe a formação docente e, indiretamente, a do próprio aluno.

As perguntas subjacentes às ponderações aqui desenvolvidas são: quem é reconhecido como cidadão e quais são os direitos dos brasileiros? Qual a visão de mundo e qual o projeto de sociedade que permeiam as propostas educacionais? A busca de resposta a essas perguntas irá fundamentar uma política de formação do professor que se paute na compreensão das condições de trabalho, na função sociopolítica e nos fins da Educação, na imaginação criadora, nas propostas pedagógicas transformadoras que visem o desenvolvimento humano integral, no diálogo multicultural e na universalização do conhecimento.

\section{Referências}

ABREU-BERNARDES, S. T. A poética na formação humana: leituras de uma educadora. 2008. 230 f. Tese (Doutorado) - Faculdade de Educação, Universidade Federal de Goiás, Goiânia, 2008.

. Relatório técnico da equipe de transição: área de educação. Uberaba: Secretaria Municipal de Educação e Universidade de Uberaba, 2004.

BACHELARD, G. 0 ar e os sonhos. São Paulo: Martins Fontes, 1990a.

A água e os sonhos: ensaio sobre a imaginação da matéria. São Paulo: Martins Fontes, 1998.

A formação do espírito científico. Rio de Janeiro: Contraponto, 1999.

BRANDÃO, C. R. A educação popular na escola cidadã. Petrópolis: Vozes, 2002.

. Refletir, discutir, propor: as dimensões de militância intelectual que há no educador. In: BRANDÃO, C. R. (Org.) Educador: vida e morte - escritos sobre uma espécie em perigo. Rio de Janeiro: Graal, 1982. p. 71-87.

BULCÃO, M. Bachelard: contribuições para uma pedagogia da razão e da imaginação. Educativa, Goiânia, v. 5, n. 2, p. $287,2002$.

CHAUÍ, M. O que é ser educador hoje? Da arte à ciência: a morte do educador. In: BRANDÃO, C. R. (Org.). Educador: vida e morte - escritos sobre uma espécie em perigo. Rio de Janeiro: Graal, 1982. p. 51-70.

DOURADO, L. F. Reforma do Estado e as políticas para a educação superior no Brasil, nos anos 90. Educação \& Sociedade, Campinas, v. 23, n. 80, p. 235-253, set. 2002.

FREITAS, L. C. Ciclo ou séries? O que muda quando se altera a forma de organizar os tempos-espaços da escola? In: REUNIÃO ANUAL DA ASSOCIAÇÃO NACIONAL DE PÓS-GRADUAÇÃO E PESQUISA EM EDUCAÇÃO, 27., 2004, Caxambu. Anais... Caxambu: ANPEd,
2004. p. 1-33. Disponível em: <http://www.anped.org.br/ reunioes/27/diversos/te_luiz_carlos_freitas.pdf>. Acesso em: 29 dez. 2008.

FABRE, M. Bachelard éducateur. Paris: Presses Universitaires de France, 1995.

GADOTTI, M. Perspectivas atuais da educação. São Paulo em Perspectiva, São Paulo, v. 14, n. 2, jun. 2000.

GRAMSCI, A. Cadernos do cárcere. Tradução de Carlos Nelson Coutinho. Rio de Janeiro: Civilização Brasileira, 2004a, v. 1.

Cadernos do cárcere. Tradução de Carlos Nelson Coutinho. Rio de Janeiro: Civilização Brasileira, 2004b, v. 2.

HOMERO. Odisseia. Tradução de Frederico Lourenço. Lisboa: Livros Cotovia, 2003.

JAEGER, W. Paidéia: a formação do homem grego. 3. ed. São Paulo: Martins Fontes, 1995.

PESSANHA, J. A. Introdução - Bachelard: as asas da imaginação. In: BACHELARD, G. O direito de sonhar. São Paulo: Martins Fontes, 1994.

PRAIS, M. L. M.; SILVA, M. E. Escola cidadã, educação: construção amorosa da cidadania: fundamentos políticos, filosóficos e pedagógicos. 2 ed. Uberaba: Prefeitura Municipal de Uberaba/Secretaria Municipal de Educação, 2000.

SILVA, J. I. Formação do educador e educação política. São Paulo: Cortez, 1992.

TOMAS, L. Ouvir o lógos: música e filosofia. São Paulo: UNESP, 2002.

Recebido em 10/03/2010

Versão final recebida em 23/07/2010

Aceito em 02/08/2010 